\title{
NAS DOBRAS DAS ONDAS DE DANIELLE FONSECA
}

Vera Maria Segurado PIMENTEL

\section{RESUMO}

O artigo, em questão, visa analisar o trabalho As dobras somos nós da artista visual, Danielle Fonseca, vencedora da XVII edição do Salão UNAMA de Pequenos Formatos, com base em autores como Lins (2009), Santaella (2003, 2007), Machado (2003), entre outros. O estudo aborda, primeiramente, um histórico do vídeo arte no Brasil, a imagem em movimento, a relação entre a teoria de Giles Deleuze das dobras com o surfe e posteriormente, uma análise a partir da semiótica aplicada sobre o vídeo em questão. As teorias sígnicas de Peirce contribuíram de maneira significativa para as análises realizadas no vídeo arte, revelando as várias relações de significados presentes nas imagens do surfista, equilibrando-se na prancha e adentrando o famoso "tubo" que todo praticante busca obsessivamente.

Palavras-chave: Surfe. Ondas. Dobras.Deleuze

\section{THE WAVES FOLD OF DANIELLE FONSECA}

\section{ABSTRACT}

The article, in question, aims to analyze the work As dobras somos nós by the visual artist, Danielle Fonseca, winner of the 17th edition of the UNAMA Small Formats Salon, based on authors such as Lins (2009), Santaella (2003, 2007), Machado (2003), among others. The study approaches, firstly, a history of video art in Brazil, the moving image, the relation between Giles Deleuze's theory of the folds with the surf and later, an analysis from the applied semiotics on the video in question. Peirce's signic theories contributed significantly to the analysis performed in video art, revealing the various relationships of meanings present in the surfer's images, balancing themselves on the board and entering the famous "tube" that every practioner seeks obsessively.

Keywords: Surf. Waves. Folds. Deleuze.

\section{EN LAS DOBLAS DE LAS ONDAS DE DANIELLE FONSECA}

\section{RESUMEN}

El artículo, en cuestión, busca analizar el trabajo. Los dobleces somos nosotros de la artista visual, Danielle Fonseca, vencedora de la XVII edición del Salón UNAMA de Pequeños Formatos, con base en autores como Lins (2009), Santaella (2003, 2007), Machado (2003), entre otros. El estudio aborda, primero, un histórico del video arte en Brasil, la imagen en movimiento, la relación entre la teoría de Giles Deleuze de los pliegues con el surf y posteriormente, un análisis a partir de la semiótica aplicada sobre el video en cuestión. Las teorías sígnicas de Peirce contribuyeron de manera significativa a los análisis realizados en el video arte, revelando las varias relaciones de significados presentes en las imágenes del surfista, equilibrándose en la tabla y adentrando el famoso "tubo" que todo practicante busca obsesivamente.

Palabras clave: Surf. Olas. Se pliega. Deleuze.

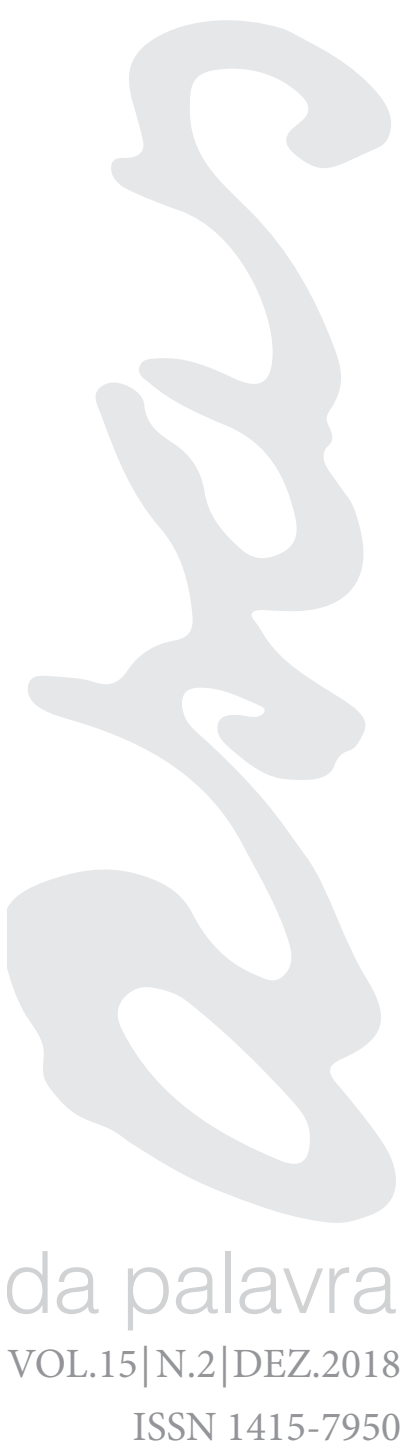




\section{INTRODUÇÃO}

A artista visual Danielle Fonseca nasceu em Belém do Pará, em 1975, iniciou seus projetos por volta de 1995 com temáticas que envolvem literatura, música e paisagem. Amante da literatura, da música e praticante do surfe, suas referências vão de Augusto e Haroldo de Campos e Décio Pignatari, músicos como John Cage, além de Brigida Baltar, Mira Schendel e os grandes artistas das ondas Gerry Lopez e Rico de Souza. Segundo a artista, em uma entrevista ao blog Surfari, em 2013, sua família sempre a incentivou no campo das artes (SURFARI, 2013).

A prática de Danielle no surfe surge na década de 1980, quando da explosão do esporte no Brasil, apesar de Belém não possuir praias. Logo, a artista sempre sentiu necessidade de buscar os mais lugares mais próximos, como a praia do Mosqueiro, na tentativa de explorar a melhor onda. $\mathrm{Na}$ entrevista, Fonseca afirma:

Aqui na Amazônia estou cercada por águas exuberantes. Surf deveria
fazer parte de nosso estilo de vida, naturalmente. Uma das coisas que
mais me fascina no surfé o fato de serem três "corpos" em movimento,
surfista, prancha e onda. E ao mesmo tempo um equilibrio perfeito en-
tre essas forças. Ver o Gerry Lopez surfar é tão bom quanto ir a um mu-
seu de arte, a força contemplativa é a mesma (BLOG SURFARI, 2013)

A trajetória artística de Fonseca vem se desdobrando desde a primeira obra de pintura, selecionada para o Salão Primeiros Passos do Centro Cultural Brasil Estados Unidos em 1995. Recebeu o Prêmio Aquisição nas versões de 2001 e 2003 do Arte Pará e de 2006 do Salão de Pequenos Formatos. De 7 de dezembro de 2005 a 31 de janeiro de 2006 realizou a individual $O$ Tao Caminho no Laboratório das Artes do Espaço Cultural Casa das Onze Janelas em Belém, como resultado de uma bolsa de pesquisa e experimentação do Instituto de Artes do Pará'.

Além desta bolsa de pesquisa, Danielle Fonseca também foi agraciada com a Bolsa de Pesquisa e Experimentação Artística do Instituto de Artes do Pará (IAP) (2005 e 2010) e Bolsa de Pesquisa em Artes Visuais da Fundação Ipiranga (PA, 2007), com os projetos Caminho de Marahú - Construção de um itinerário poético e real até a cabana de Max Martins, As ondas: um encontro de escorrego entre arte e surfe, e Rumo ao Farol: $O$ destino da palavra é tornar-se água. (SOBRAL e MANESCHY, 2014).

Muito atuante no cenário das artes visuais local e nacional, Fonseca tem participado de várias exposições coletivas, como exemplo: Amazônia Lugar da Experiência, Museu da UFPA (Belém,2012,2013); Outra Natureza, Espaço Cultural BASA (PA, 2013); Cromomuseu, Museu de Arte do Rio Grande do Sul (MARGS, 2012); O Triunfo do Contemporâneo, Santander Cultural (Porto Alegre, 2012); Corpo incógnito - água viva, Galeria Amarelonegro Arte Contemporânea (RJ, 2012); Sobre ilhas e pontes, Galeria Cândido Portinari (RJ, 2010); FOTORIO 2009, Espaço Oi Futuro (RJ, 2009);

1 Fonte: Entrevista ao blog SURFARI. Disponível em: $<$ http:// amazoniacontemporanea.blogspot. com/2008/01/danielle-fonsecabelm-1975.html Acesso 28 jul2018.

2 Fonte: PIPA: Uma Janela para a Arte Contemporânea Brasileira. Disponível em:< http://www. premiopipa.com/2017/06/daniellefonseca-mistura-aquarelasfotografias-escultura-e-filme-emindividual/> Acesso em 11jul2018

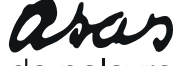

VOL. 15 | N.2 | DEZ. 2018 ISSN 1415-7950 $12^{\circ}$ Salão da Bahia (2005) e Faxinal das artes, Museu de Arte Contemporânea - MAC (PR, 2002).

Como exposições individuais, pode-se citar Contraia os olhos: subitamente o ar parece estar mais salgado, na galeria Kamara Kó, com curadoria de Daniel Lins em 2013 e Sabe, eu já estive no mar antes na mesma galeria em 2017, cuja curadoria esteve a cargo de Bárbara Palha e texto crítico do curador do Museu de Arte Contemporânea de Niterói, Raphael Fonseca. Para o crítico, o trabalho de Danielle Fonseca, "se articula essencialmente na relação entre imagem e texto. Além de ser uma criadora dentro das chamadas 'artes visuais', a artista se caracteriza também pela sua produção como escritora" .

As pesquisas e os resultados dos projetos de Danielle Fonseca 
surpreendem os espectadores pelas temáticas bem frequentes relacionadas às letras. Nesta última exposição, a artista se supera ao buscar nas palavras dos versos do cantor Joni Mitchel, sua inspiração para dar nome a mostra. Por todos esses processos em construção, vale ressaltar que Danielle já teve seu nome indicado para a $7^{\mathrm{a}}$ versão do Prêmio Pipa no ano de 2016, considerado o mais relevante prêmio de artes visuais brasileira.

Como citado anteriormente, o vídeo A dobra somos nós é a continuação de uma pesquisa realizada para o seu filme $A$ Vaga, em que conjuga surfe, filosofia e arte, tendo como base o texto Deleuze: o surfista da imanência, do filósofo, sociólogo e psicanalista Daniel Lins, para quem surfar é criar movimento. Para Lins, que pratica bodyboard há mais de 20 anos, o surfista sobre a onda, quase inerte, está em movimento, e a inércia é o silêncio que pode se transformar em devir.

Após essa introdução sobre o início e a trajetória artística de Danielle Fonseca, o estudo se propõe revelar, primeiramente, o histórico do vídeo arte no Brasil, a fim de contextualizar um suporte e um fazer artístico tão explorado no circuito das artes; apresentar o surfe como modalidade esportiva; enfatizar a relação do discurso de Deleuze sore a teoria da dobra e o surfe e posteriormente analisar o vídeo, a partir da semiótica aplicada.

\section{A VIDEO ARTE NO BRASIL}

Ao se abordar vídeo arte no Brasil, há necessidade de verificar como, onde e quando esse novo fazer artístico surge e se torna um dos suportes mais requisitados pelos artistas na arte contemporânea nacional e internacional.

Segundo Santaella (2003), a arte para ser produzida, depende dos suportes que as sustentam, que historicamente vem sendo reinventados. A arte tecnológica ocorre da produção do artista por meio de "aparelhos" (FLUSSER, 1985 apud SANTAELLA, 2003), ou seja máquinas de linguagem que dão "corpo a um saber técnico introjetados nos seus próprios dispositivos materiais" (SANTAELLA, 2003, p. 153). O aparelhamento tecnológico se inicia com a câmera fotográfica, cujos conhecimentos no campo da óptica, da mecânica e da química impactaram os contextos sociais, culturais e artísticos provocados pelas imagens instantâneas materializadas na fotografia.

A partir da fotografia e durante o período futurista, muitos artistas iniciaram a busca pela inserção de novas tecnologias na produção artística. Assim, com a afirmação da fotografia e do cinema experimental nas primeiras décadas do século XX, e os trabalhos cibernéticos de Nam June Paik, em que utiliza monitores de TV com imagens correndo nas telas, insere-se no cenário artístico, as vídeo instalações e vídeo performances, como na obra de Joan Jones em 1972 (SANTAELLA, 2003).

Com o surgimento em meados do século XXI dos equipamentos portáteis de vídeo, abrem-se as portas para um novo fazer artístico: a vídeo arte, cujo iniciador foi Nam June Paik, que ligou um aparelho de vídeo portapak e acompanhou a visita do Papa pelas ruas de Nova Iorque e o passou na mesma noite no Café a Go Go (SANTAELLA, 2003).

No Brasil, década de 1970, plena Ditadura Militar, cenário de grandes turbulências políticas por meio de manifestações de diversos segmentos da sociedade, muitas vozes foram caladas e vários artistasativistas exilados. Em virtude da proibição da exposição, no Museu de Arte do Rio de Janeiro, de alguns artistas selecionados para VI Bienal de Paris, uma grande manifestação, liderada pela Associação Brasileira de Críticos de Arte, resultou no boicote à Bienal de São Paulo, perdurando até o início da década de 1980 (JAREMTCHUK, 2007 apud ALMEIDA, 2017).

De acordo com Machado (2003), o vídeo surge no Brasil oficialmente 
em 1974, quando foram realizados os primeiros videoteipes por uma geração de artistas, convidados a participar de uma mostra de vídeo arte na Filadélfia. Isso só foi possível, graças a intermediação de Jom Tob Azulay, que coloca à disposição de alguns artistas, como Sônia Andrade, Fernando Cocchiarale, Ana Bella Geiger e Ivens Machado, um aparelho portátil portapack. Além desses iniciadores, outros trilharam o mesmo caminho, como: Paulo Herkenhoff, Letícia Parente e Miriam Danowski, todos pertencentes ao contexto carioca.

Em São Paulo, os primeiros trabalhos apareceram em 1976, no Museu de Arte Contemporânea da Universidade de São Paulo - MAC/USP, dirigido, então, por Walter Zanini, um grande incentivador e entusiasta da vídeo arte, que disponibilizou um aparelho portapack para os seguintes artistas: Regina Silveira, Julio Plaza, Carmela Gross, Donato Ferrari, Gabriel Borba, Marcelo Nitsche, Gastão de Magalhães e Geraldo Anhaia de Mello. (MACHADO, 2003).

Assim, as experimentações estéticas por meio das tecnologias se expandiram e o vídeo foi:

Uma tecnologia de baixo custo de produção, de sua absoluta independência em relação a laboratórios de revelação ou de sonorização (que funcionavam como centros de vigilância da produção na época da ditadura militar) e sobretudo pelas características lábeis e anamórficas da imagem eletrônica, mais adequada a um tratamento plástico. (MACHADO, 2003, p. 9)

Um detalhe a ser revelado é que, apesar de inovador como ferramenta e suporte para os novos trabalhos artísticos que surgiam, muitos artistas que iniciaram alguns trabalhos na vídeo arte não deram continuidade. Dentre os que se mantiveram nessa trajetória, pode-se citar Rafael França, um gaúcho meio deslocado no circuito brasileiro, por não fazer parte do eixo Rio-São Paulo, cujos projetos se estabeleceram nos cenários de Chicago, onde estudou e lecionou.

O artista, participante da segunda geração de vídeo independente, tinha como meta principal, a conquista do espaço na televisão. Assim, para França, o vídeo era uma operação de "radicalidade e densidade significante, que jamais poderia penetrar sem concessões na tela doméstica" (MACHADO, 2003 , p. 9). França, além de ser considerado um dos primeiros pesquisadores em vídeo no Brasil, também revelou criativamente, como adequar criação plástica e acústica com o meio (MACHADO, 2003).

A partir da década de 1980, a vídeo arte começa a tomar um novo caminho, na busca de um público maior, com o início de festivais. Desse modo, pode-se citar o primeiro e mais importante, conhecido por Vídeobrasil, idealizado por Solange Oliveira Farkas, ativo por mais de 20 anos, além de terem surgido as primeiras salas de exibição de vídeos, numa tentativa de romper com os feudos das redes de televisão (MACHADO, 2003).

Vale ressaltar nesse época, o surgimento do TVDO (leia-se "Tv Tudo") constituído por alguns videastas como Tadeu Jungle, Walter Silveira, Ney Marcondes, Paulo Priolli e Pedro Vieira. Esse grupo foi responsável pelas maiores experiências em vídeos, operando entre a cultura popular e a erudita, além as intervenções críticas nas realidades do país. (MACHADO, 2003).

Outro grupo que surge no mesmo período foi o Olhar Eletrônico, formado por Marcelo Machado, Fernando Meirelles, Renato Barbieri, Paulo Morelli e Marcelo Tas. O grupo realizava "vídeos curtos, de no máximo 3 a 4 minutos, cuja técnica se baseava na montagem acelerada, com planos breves e cortados em ritmos sincopados" (MACHADO, 2003, p. 11). O diferencial encontrado nos trabalhos desse grupo se estabelece na linguagem poética desenvolvida e nos documentários de cunho social apresentados. (MACHADO, 2003). 
computadores, transformando obras, ainda expostas por meios tradicionais, em imagens manipuladas digitalmente, com fluxos interativos, numa relação muito próxima do computador com a televisão (SANTAELLA, 2003). Assim, a vídeo arte segue uma trajetória mais interativa, realizada por meio de softwares e outros programas digitais. Os artistas trilharam o caminho do cinema, outros preferiram os museus e as galerias, além dos que aderiram a criação de websites, webdocumentários ${ }^{3}$, entre outros.

A tendência atual da vídeo arte é a interatividade, tornando o espectador muito mais um coautor, a partir de maior proximidade com a obra. A vídeo arte é uma ideia condensada transmitida pela ferramenta audiovisual, mutável, menos museificada. Para França (1997), ao invés de se dizer "Favor não tocar", hoje se usa "Favor tocar" ou "Favor Pisar", "pois a obra só está completa em contato direto com a criação intelectual do observador e sua correspondente resposta"4.

\section{A IMAGEM EM MOVIMENTO}

Ao se abordar imagem e movimento, vale ressaltar duas ideias muito importantes relacionadas a esse tópico. Para alguns teóricos, a imagem digital é um simulacro, apresentada como uma pretensa cópia. Para outros, é um código binário alojado em um computador (BRAGA, 2010). Em uma terceira ideia, pode-se inferir que a imagem digital é "um fenômeno portador de uma realidade ontológica e epistemológica. Trata-se de compreendê-la como fluxo, movimento".

Braga $(2010)^{5}$ afirma que:

\begin{abstract}
A imagem digital por sua natureza de matriz manipulável engendra sempre um movimento, seja de natureza interna ou externa. Interna como as experiências de Motion graphics. Externas como a Hipermídia. Mesmo quando parada, a imagem digital pode ser concebida como um movimento infinitamente pequeno, virtual.
\end{abstract}

De acordo com o autor citado, a fenomenologia de Bergson tornase importante fundamento para que se possa entender esse processo, a partir das análises que Gilles Deleuze realiza e investiga sobre este teórico (BRAGA, 2010). Deleuze (1995 apud OLIVEIRA, 2011), ao adentrar as teorias de Bergson sobre o movimento, alerta que não há apenas uma tese do movimento, mas três. Na primeira tese, o movimento não se confunde com o espaço percorrido, pois "o espaço percorrido é divisível, e até infinitamente divisível, enquanto o movimento é indivisível, ou não se divide sem mudar de natureza a cada divisão" (DELEUZE, 1985 apud OLIVEIRA, 2011, p. 2).

Em relação a essa tese, Oliveira $(2011$, p. 3) aborda a corrida de Aquiles e a tartaruga de Zenão de Eléia, em que de acordo com Deleuze, Aquiles conquista a vitória por se considerar que "o movimento dos passos de Aquiles e da tartaruga seja tomado como indivisível e heterogêneo, em relação ao espaço percorrido - que é divisível e homogêneo".

A segunda tese se refere a duas situações distintas: a primeira

concebe o movimento remetendo-o a uma ordem de instantes privilegiados, como em Aristóteles; o outro é o da ciência moderna, que ao invés de pensar o movimento sob a ordem do instante privilegiado, o coloca no instante qualquer de uma trajetória" (OLIVEIRA, 2011, p. 3)

Para Deleuze (1985 apud OLIVEIRA, 2011), a ideia da ciência moderna privilegia o tempo, ainda que considerado pequeno, pois o tempo fica reduzido a um modelo espacial.

A terceira tese aborda o movimento como expressão de mudança
3 Fonte: paleonerd.com.br/2015/06/21/ voce-sabe-o-que-e-video-arte. Acesso 18jul2018

4 Idem

5 BRAGA, Eduardo. Imagem digital: imagem-movimento e a fenomenologia bergsoniana. In: Concept Philosophy: Art, Design and Communication. Disponível em: www.edubraga. pro.br/estetica-aesthetics/imagemdigital-imagem-movimento-e-afenomenologia-bergsoniana/. Acesso em: 31 jul2018. 
no todo, ou seja, "o movimento é um corte móvel da duração do todo". (DELEUZE, 1985 apud Oliveira, 2011, p. 4). Para Deleuze, o movimento remete sempre a uma mudança, uma migração, uma variação sazonal, como ele explica:

A imagem movimento tem duas faces, uma em relação a objetos cuja
posição ela faz variar, a outra em relação a um todo cuja mudança ab-
soluta ela exprime. As posições estão no espaço, mas o todo que muda
está no tempo. Se assimilarmos a imagem movimento ao plano, cha-
maremos de enquadramento à primeira face do plano, voltada para os
objetos, e de montagem à outra face, voltada para o todo (DELEUZE,
$2009, p$. 48 apud OLIVEIRA, 2011, p.5)

Assim, a partir das análises acima, pode-se inferir que as teorias de Bergson investigadas por Deleuze podem ser aplicadas ao vídeo, visto se pensar a relação entre movimento e tempo, a partir de um elemento: a imagem (OLIVEIRA, 2011). Cinema e vídeo exprimem movimento, ação em cima de imagens, diferentemente da fotografia, em que a imagem é estática. Portanto, cabe ao cineasta transformar ideias, pensamentos ou conceitos em imagens, desse modo, a vídeo arte possui uma ligação com o pensamento, onde o próprio pensar e criar imagens envolve sempre o movimento e o tempo em seu pensamento e em sua criação (OLIVEIRA, 2011).

\section{DELEUZE E O SURFE}

Gilles Deleuze foi um filósofo francês, nascido em 1925 em Paris e falecido em 1995, na mesma cidade. Oriundo de uma família de classe média, Deleuze estudou Filosofia na Universidade de Sorbonne e foi professor, primeiramente nos liceus franceses e depois nas Universidades de Lyon, Paris VIII e Vicennes.

De personalidade excêntrica, Deleuze sempre foi muito reservado, não sendo chegado a entrevistas e muitas revelações de sua vida particular, pois achava que suas obras eram bem mais importantes do que outros assuntos privados. Sua saúde sempre inspirou muitos cuidados, pois desde cedo sofreu com problemas respiratórios, chegando a desenvolver tuberculose em 1968. Tais problemas, acometidos ao longo de sua existência, foram piorando com o passar do tempo, prejudicando inclusive suas atividades acadêmicas.

A partir de 1992, Deleuze já bem fragilizado, com apenas $1 / 3$ da capacidade respiratória, passou a viver bem isolado em seu apartamento. Em 04 de novembro de 1995, respirando apenas com ajuda de aparelhos, o filósofo não suportando mais viver nas condições subumanas, jogou-se da janela de seu apartamento em Paris, deixando dois livros inacabados ${ }^{7}$.

Apesar de nunca ter praticado, Deleuze conheceu o surfe, esporte 6 Fonte: Razão Inadequada. que significa o desenvolvimento da alegria pelo corpo, pois surfar é criar Disponível em $<$ razaoinadequada. movimento (LINS, 2009) ${ }^{8}$. Segundo Lins (2009)9

com/filósofos-essenciais/deleuze/>

Acesso em:23jul2018
7 Idem

8 Fonte: LINS, Daniel. Deleuze

o surfista da imanência. IN:

O Vertebral. Disponível em: $<$ overtebral.blogspot.com $>$ Acesso em 23jul2018

9 Idem

10 Idem

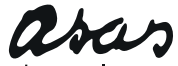
da palavra ISSN 1415-7950 da palavra ISSN 1415-7950

O que qualifica um bom surfista, é pois, a facilidade com a qual ele realiza o seu movimento numa superficie de jogo pertencente a uma velocidade nomade do movimento e do tempo da onda. [...] ele brinca de brincar com a onda, excedendo os limites da própria onda e de suas regras não estabelecidas.

O surfista supera os limites do seu corpo e da própria onda para manter equilíbrio por meio do movimento necessário das dobras do corpo. Esse movimento sobre a superfície pode ser comparado a um pensamento, que Deleuze cita como o "jogo ideal", pensamento que extrapola os limites, como o surf e o surfista, no balançar e atravessar das ondas ${ }^{10}$.

O "jogo ideal" não possui regras, vencedor ou vencidos; o mar não 
tubo é para ele, o experimento da imanência. O surfista é a onda com a onda e não a onda sobre a onda; ele se realiza afirmando o acaso, é um puro sensitivo à escuta do meio no qual ele dança com seu corpo-onda para não "dançar" na vida (LINS, 2009.)

Essa interação Deleuze, surfe e filosofia se inicia a partir da procura de Gibus de Soultrait por Deleuze, em que nasce uma correspondência virtual/ real. Assim, Soultrait cita que, nunca imaginou que aquele ser frágil poderia se interessar em conhecer o surfe que, ao participar da Noite do escorrego com vários praticantes do esporte, escreveu: "Fui ao Rex, o público jovem despertou uma mistura de angústia (leve) e de jubilação, mas, sobretudo, os filmes me impressionaram muito. Há ali, evidentemente, uma combinação matéria-movimento muito nova. Estou certo de que a filosofia é concernida pelo surf". ${ }^{11}$

Assim, Deleuze inicia uma curta interação entre a teoria das dobras de Leibniz e a física quântica com o corpo dos surfistas, curta pelo fato de já estar muito debilitado pela doença. Para o filósofo, o surf era vida, alegria, vibração, onde "o oceano é o livro do surfista, sua prancha uma caneta, e cada onda um poema." (LINS, 2009) ${ }^{12}$

\section{"AS DOBRAS SOMOS NÓS"}

O trabalho A dobra somos nós é a continuação de uma pesquisa realizada por Danielle Fonseca para o seu filme $A$ Vaga, em que conjuga surfe filosofia e arte, tendo como base o texto Deleuze: o surfista da imanência, do filósofo, sociólogo e psicanalista Daniel Lins, para quem surfar é criar movimento.

No vídeo premiado, a artista procura transmitir em 40 segundos, a visão de um rapaz bronzeado, que se equilibra em uma prancha de surf por meio dos tubos formados pelas ondas gigantes do mar da Indonésia. Ao lado da tela, uma caixa com parafina e objetos usados pelos surfistas para o preparo das pranchas. Observando a imagem, pode-se escutar o som do mar que transforma o cenário de iminente perigo em uma atmosfera poética do equilíbrio contra as forças da natureza. A artista privilegia os movimentos do corpo do surfista.

Segundo Danielle Fonseca, o trabalho foi iniciado por meio de convites nas redes sociais para que pessoas ou praticantes de surfe que tivessem vídeos sobre o tema os enviassem para o e-mail da artista. Dessa forma, um autor desconhecido da Indonésia se autorregistrou e enviou as imagens que a artista se apropriou para realizar o seu trabalho. A intenção de Danielle Fonseca, ao criar o vídeo, era envolver o espectador com a cena do surfista em movimento, fazê-lo entrar no tubo da onda e sentir as mesmas emoções do surfista.

O vídeo destacou-se não só pela temática em si, mas por toda a proposta conceitual e prática que previa os detalhes da montagem, como a cor da parede em azul petróleo igual da caixa de madeira onde foi inserido o aparelho de TV. A unificação da cor da parede com a da caixa permitiu que apenas o som e a imagem se sobressaíssem, como se não houvesse mais nada ao redor, apenas os movimentos das ondas e do surfista, o que demonstra um grande cuidado da artista na construção da obra.

Para elaboração deste trabalho, Danielle Fonseca buscou inspiração no seu amor pelo surfe, como praticamente e nos textos As Ondas de Virginia Woolf e Deleuze: O surfista da imanência do filósofo Daniel Lins, como a própria artista explica:

As palavras do livro 'As Ondas' da escritora inglesa Virginia Woolf já me levavam a uma entrega literária e de certa maneira vez ou outra me fazia pensar na minha relação com a praia, o mar, as ondas e o surf. Mas, após ler o texto 'Deleuze: O surfista da imanência'do
11 Fonte: LINS, Daniel. Deleuze o surfista da imanência. IN: O Vertebral. Disponível em: <overtebral.blogspot. com>Acesso em 23jul2018

12 Idem

13 Fonte: http://experienciamazonia org/site/artistas/danielle-fonseca/Surfe-Pensamento-Danielle-Fonseca.pdf. Acesso 25jul2018

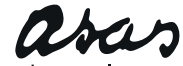

da palavra 
filósofo Daniel Lins, percebi que o surf pertencia a outro campo, além dos esportes, o campo do pensamento. Mas, como discutir a relação entre a arte contemporânea, a filosofia e o surf, sem fazer a tão comum apologia de uma prática radical, de apenas tratá-lo como esporte de aventura? Tratá-lo nesse campo era abrir mão da estética do extremo e do efêmero que alguns esportes inspiram. ${ }^{13}$

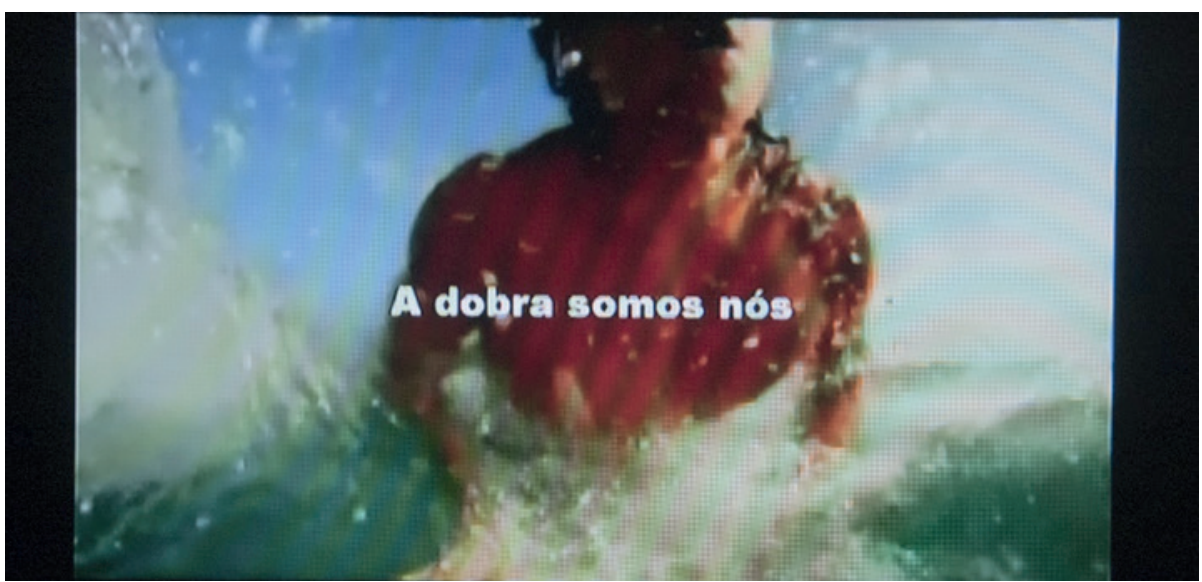

Fig. 01. A Dobra somos Nós - Vídeo Instalação - 2010. Fotografia: Helder Leite, 2011

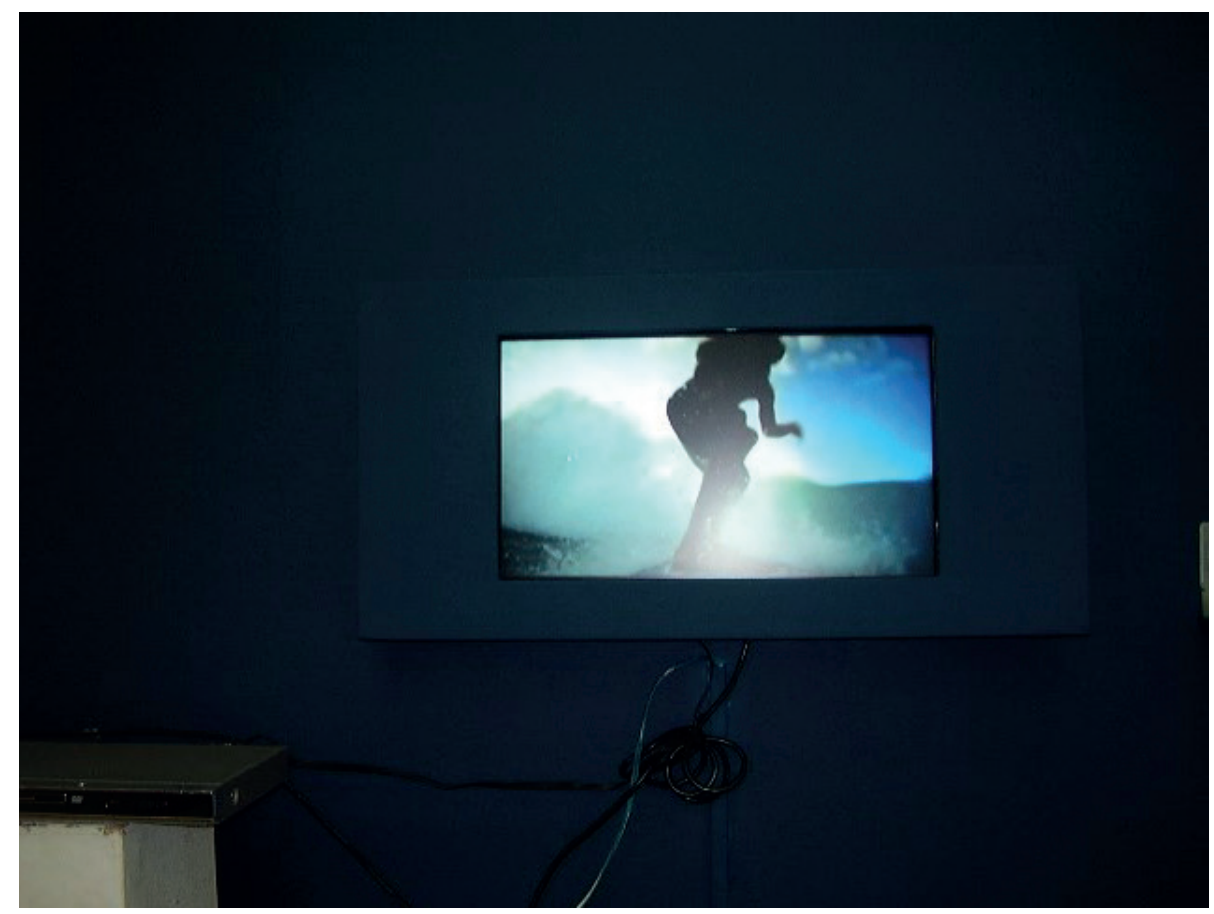

Fig. 02. A dobra somos nós.

Fotografia: Helder Leite, 2011.

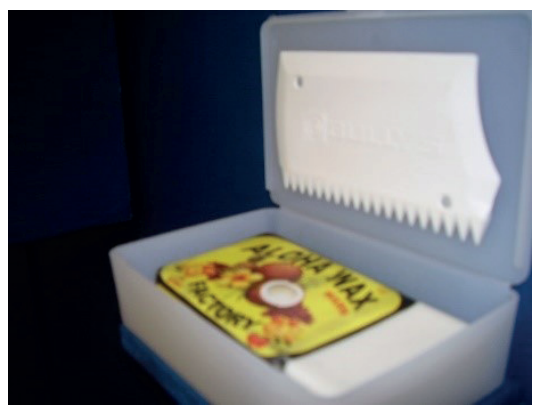

Fig. 03. Parafina. Fotografia: Helder Leite, 2011 
As teorias semióticas aplicadas de Charles Sanders Peirce serviram de base para análise dessa vídeo arte de Danielle Fonseca, a partir das classificações do signo. Segundo Santaella (1998, p. 13), foram apresentadas 10 tricotomias do signo, porém Peirce se dedicou principalmente a três: "a relação do signo consigo mesmo $\left(1^{\circ}\right)$, a relação do signo com seu objeto dinâmico $\left(2^{\circ}\right)$ e a relação do signo com seu interpretante $\left(3^{\circ}\right)$, que se caracterizam também como quali-signo (ícone), sin-signo (índice) e o legisigno (símbolo).

Assim, inicia-se a análise no quali-signo ou ícone, a partir da cor da parede e da caixa onde a TV foi inserida em azul petróleo, para que a imagem, o seu brilho e o som se destacassem na escuridão do espaço expositivo. Segundo o site EVONLINE ${ }^{14}$, sobre o significado das cores, o azul escuro demonstra poder e confiança, muito adequado para o contexto, sugerindo que a imagem do surfista no tubo da onda é de muita autoconfiança. O título A dobra somos nós sugere o movimento de dobras do corpo do surfista para se manter equilibrado sobre as ondas.

O efeito mais impactante do vídeo está no brilhante azul do mar e no momento que o surfista adentra o tubo da onda, mais uma vez sugerindo o poder do surfista por conseguir dominar este fenômeno da natureza, equilibrando-se em uma prancha de madeira.

Em relação ao sin-signo ou índice, o título As dobras somos nós indica a relação da vídeo arte com o amor da artista pelo surfe, em que para delinear o movimento é necessário muita segurança, autonomia, equilíbrio, poder e principalmente domínio deste fenômeno da natureza. O surfista se dobra, se contorce e equilibra-se em movimentos muito rápidos. A imagem apresenta um azul muito brilhante, que destaca não só a grandiosidade da onda e do mar, mas principalmente, os movimentos que o surfista apresenta para manter o total domínio e controle do tubo. A escova indica a necessidade de passar a parafina na prancha a fim de criar mais aderência e manter o equilíbrio do praticante em cima dela. Ondas indicam movimentos provocados pelo vento, que sopra sobre a superfície das águas oceânicas. Já a dobra da onda indica o momento que ela se aproxima do litoral, quebra-se e se espalha pelas areias da praia.

Para o ponto de vista convencional simbólico, o título se relaciona às dobras que segundo Gilles Deleuze, os surfistas dizem:

Estamos sempre nos insinuando nas dobras da natureza. Para nós, a natureza é um conjunto de dobras móveis. Nós nos insinuamos na dobra da onda, habitar a dobra da onda é a nossa tarefa. Habitar a dobra da onda e, com efeito, eles falam disso de modo admirável. ${ }^{15}$

O azul petróleo da caixa e da parede representam o poder e o domínio do surfista sobre a onda, o equilíbrio. O movimento dos corpos e das ondas se dobram conjuntamente, como nunca dança, em que há parceiros e esses parceiros são o surfista e as ondas. Ondas significam elevações formadas nos rios e mares, chamados também de vaga. Essas elevações em conjunto representam cadeias que vão se movimentando e se desdobrando até alcançar o cume, como se fosse uma montanha ou uma duna de areia em movimentos ondulados provocados pelo vento.

Para o surfista, entrar no tubo da onda é chegar ao ápice do esporte e significa estar cercado de água salgada por todos os lados, sem ao menos toca-la, é estar envolvido pela força da natureza, sem atrapalhar seu curso natural. Tubo é algo cilíndrico e oco pelo qual passam líquidos ou gases, às vezes, estreito ou largo, que desafia àquele que tenta ultrapassá-lo. Assim, o tubo para o surfista envolve sentimentos, emoções que podem durar um mínimo de tempo para o espectador, mas uma eternidade para quem o adentra. Após a primeira entrada no tubo, o praticante do surfe se torna um obcecado, na busca constante das "cavernas aquáticas" ${ }^{16}$. O mar simboliza
14 Fonte: EVOLINE. Simbologia das cores. Disponível em: <www. evonline..com.br $>$. Acesso 30jul2018

15 Fonte: $<$ http://experienciamazonia org/site/artistas/danielle-fonseca/Surfe-Pensamento-Danielle-Fonseca.pdf $>$. Acesso 30jul2018

16 Fonte: Por trás da Onda Disponível em: $<$ https://dosurf.com. br/2016/02/22/o-tubo/s. Acesso em: 31 jul2018 
para o surfista o ar que ele respira e as ondas são o alimento que o fazem crescer e dominá-las cada vez mais, revelando todo o seu poder em conquistála e superá-la. afirma:

Por fim, Danielle Fonseca (2010), no seu texto Surfe é Pensamento,

\begin{abstract}
Acredito estar em busca de um caminho onde possa apresentar o surf como uma expressão de singularidade artística de tal maneira que ele fique próximo da arte ou do pensamento artístico. Surfar é criar movimento. Arte é criação. Podemos encontrar entre o surfe a arte contemporânea certa performance no comportamento, pois assim como na dança, convenhamos "o surfista é um equilibrista dançarino de uma cena líquida" 17
\end{abstract}

\section{CONSIDERAÇÕES FINAIS}

O artigo, em questão, procurou analisar com base nos estudos semióticos de Peirce, a vídeo arte As dobras somos nós, da artista paraense Danielle Fonseca, vencedora da $17^{\mathrm{a}}$ versão do Salão UNAMA de Pequenos Formatos. A artista visual, apaixonada e praticante do surfe, relaciona aos movimentos executados pelo surfista para manter o equilíbrio e o domínio sobre as ondas, como dobras, com base no texto, Deleuze: o surfista da imanência de Daniel Lins, outro praticante do esporte há mais de 20 anos.

No texto de Lins (2009), Fonseca encontrou inspiração para transformar filosofia e surfe em vídeo arte brilhantemente, a partir das dobras citadas por Deleuze:

\begin{abstract}
A desdobra não é o contrário da dobra, mas segue as dobras até outra dobra. Dobras de vento, de águas, do fogo e da terra, e dobras subterrâneas de filões na mina. Os desdobramentos sólidos da 'geografia humana' remetem, inicialmente, à ação do fogo e, depois, à ação das águas e dos ventos sobre a terra, um sistema de interações complexas. (DELEUZE apud LINS, 2009) ${ }^{18}$
\end{abstract}

Deleuze também adentrou o mundo do surfe ao ser procurado pelo surfista Gibus de Soultrait, e a partir daí manter uma correspondência virtual/ real para assim conhecer um pouco mais sobre esse esporte. Por já estar com a saúde bastante fragilizada, Deleuze não teve tempo de se infiltrar ainda mais nesse mundo e poder contribuir com suas ideias. Todavia, o pouco que pode foi de grande relevância, pois, tornou-se um influenciador dos seus pensamentos.

Percebe-se que Danielle Fonseca executou todo processo e a pesquisa para a construção dessa obra com muito critério e cuidado, nas mesmas trilhas que a fizeram despontar no circuito de artes local e nacional. A busca pela melhor performance sobre as ondas por meio das redes sociais, as conversas virtuais com Soultrait, a relação às ideias de Deleuze sobre as dobras e o surfe por meio das palavras de Lins, revelam todo um processo de construção artística, que não surgiram instantaneamente.

Esse processo foi construído por etapas, numa imersão de pesquisa de literatura e esporte, em que o corpo performático do surfista e as dobras nos movimentos que ele realiza são os personagens principais. Sem dúvida nenhuma, na sala escura em que foi exposto, o vídeo impactava pelo brilho, pela profundidade do azul do mar e mais ainda, pelos movimentos desenhados pelo corpo do surfista, ao ser "engolido" pelo tubo da onda.

Para o júri que o elegeu vencedor, os diferentes elementos que jurados pela autora, após a nomeação da obra vencedora no $17^{\circ}$ Salão Unama de Pequenos Formatos em 2011.

compõem o trabalho se encontram muito bem resolvidos na obra, desde o título, à forma de apresentação e do conteúdo. De acordo Elza Lima ${ }^{19}$, a imagem inter-relaciona "filosofia, maleabilidade do corpo, desvela o encontro

VOL. $15 \mid$ N.2 | DEZ.2018 sublime entre a água e o corpo". Para a jurada, há aqui a questão da ação da palavra ISSN 1415-7950 desenvolvida pelos atletas, meio marginalizada e principalmente a simbiose 
do encontro do homem com a natureza.

Armando Queiroz explica a sua opção pelo fato de que "há uma excelência na obra, percebe-se como a artista pode trabalhar de maneira lúcida e madura sua poética; ela ultrapassa as questões plásticas." Geraldo Teixeira destaca a subjetividade do vídeo. Ressalta que na imagem fica visível uma carga de conceitos opostos, não fáceis de interpretar no processo de trabalho desenvolvido pela artista.

As análises do júri estiveram em sintonia, os três concordaram que a obra de Danielle Fonseca apresenta um dado instigante ao relacionar filosofia, movimento e corpo. Arte e esporte ficam em consonância, tendo o corpo como eixo e dotam o vídeo de uma linguagem que atravessa temas distintos, mas em consonância com a hibridez da arte contemporânea, principalmente com a literatura (MAX MARTINS, 1926 - 2009) e a música (JOHN CAGE, 1912 - 1992).

Assim, o trabalho da artista se destaca, não só por todos esses fatores expostos, mas principalmente, por toda a pesquisa que a artista se "debruça" e abraça, com a finalidade de revelar a importância do esporte, da literatura e da filosofia em consonância com a arte. Como cita Sobral e Maneschy (2014, p. 3.370), "a artista, essa acqua-woman, através de seu trabalho nos lança desafios, intensifica sensações, desperta vontades, dessa entrega do artista, desse mergulho profundo e interior. Nos encanta, e, certamente nos salga os olhos".

\section{REFERÊNCIAS}

ALMEIDA, Thamara. A VIDEOARTE NO BRASIL: Uma perspectiva histórica o Festival Videobrasil e a trajetória de Eder Santos como estudos de caso. Programa de Pós-graduação em Artes, Cultura e Linguagens. Teorias e Processos Poéticos Interdisciplinares, do Instituto de Arte e Design, da Universidade Federal de Juiz de Fora, MG, 2017.160p.

BRAGA, Eduardo. Imagem digital: imagem-movimento e a fenomenologia bergsoniana. In: Concept Philosophy: Art, Design and Communication. Disponível em: www.edubraga.pro.br/estetica-aesthetics/imagem-digital-imagem-movimentoe-a-fenomenologia-bergsoniana/. Acesso em: 31jul 2018.

DUBOIS, Philipe. Cinema, vídeo, Godard. São Paulo: Editora Cosac Naify, 2014.

EVOLINE. Simbologia das cores. Disponível em: <www.evonline..com.br>. Acesso 30 jul 2018

Surf e Pensamento. In: Experiência Amazonica.org. Disponível em: <http://experienciamazonia.org/site/artistas/danielle-fonseca/Surfe-Pensamento-Danielle-Fonseca.pdf.> Acesso 25 jul 2018.

FONSECA, Danielle. Porto Alegre: Revista Surfari. Entrevista cedida a Lucas Zuch. [08/04/2013]. Disponível em http://www.surfari.com.br/surfari-entrevistadanielle-fonseca. Acesso em: 28 jul 2018

LINS, Daniel. Deleuze surfista da imanência. In: O Vertebral. Disponível em: $<$ overtebral.blogspot.com>Acesso em 23 jul 2018.

MACHADO, Arlindo (org.). Made in Brasil: três décadas do vídeo brasileiro. Curador Arlindo Machado; Texto Walter Zanini, Fernando Cocchiarale, Cacilda Teixeira da Costa et al.. São Paulo: Itaú Cultural, 2003. 275 p., il. p\&b.

MACHADO, Arlindo (Org.). Made in Brasil: Três Décadas do Vídeo Brasileiro. Itaú Cultural. São Paulo: Iluminuras, 2007.

OLIVEIRA, Leonardo. Filosofia e Cinema em Deleuze: Da Imagem-Movimento 
às Condições de sua Superação. In: Revista Pandora Brasil-Número 34, Setembro de 2011, p.1-13.

PIMENTEL, V. M. S. O Salão De Pequenos Formatos (2010 - 2011): Processos de análise e considerações. Dissertação. Programa de Pós Graduação em Comunicação, Linguagem e Cultura - Universidade da Amazônia, 2012.

PIPA: Uma Janela para a Arte Contemporânea Brasileira. Disponível em: $<$ http:// www.premiopipa.com/2017/06/danielle-fonseca-mistura-aquarelas-fotografiasescultura-e-filme-em-individual/> Acesso em 11jul2018.

Por Trás Da Onda. O Tubo. Disponível em:< https://dosurf.com.br/2016/02/22/otubo/>. Acesso em: 31 jul2018.

Razão Inadequada. DELEUZE. Disponível em $<$ razaoinadequada.com/filósofosessenciais/deleuze/> Acesso em:23jul2018.

SANTAELLA, Lucia. Cultura das mídias. 4a. ed. São Paulo: Experimento, 1992 [2003a].

Culturas e artes do pós-humano: Da cultura das mídias à cibercultura. São Paulo: Paulus, 2003b.

SOBRAL, Keyla; MANESCHY, Orlando. Danielle Fonseca: O Corpo Performático da Artista-Surfista nas Águas da Amazônia. In: $23^{\circ}$ Encontro da ANPAP - "Ecossistemas Artísticos" -15 a 19 de setembro de 2014 - Belo Horizonte - MG, 2014.

Doutoranda em Comunicação, Linguagem e Cultura - UNAMA (2018); mestre em Comunicação, Linguagens e Cultura pela Universidade da Amazônia (2012); especialista em Linguística aplicada à Língua Inglesa - UNAMA (2002); graduação em Letras - Habilitação em Inglês- UNAMA (2002), graduação em Educação Artística pela Universidade Federal do Pará (1985). Atualmente é professor adjunto I da Universidade da Amazônia, professor titular da Faculdade Metropolitana da Amazônia e em processo de aposentadoria da Secretaria de Educação do Estado do Pará. Tem experiência na área de Artes, com ênfase em História da Arte, em Comunicação, Língua Inglesa, Português e Redação, Metodologia Científica e tutora em EAD. Email: pimentel106@hotmail.com 